\title{
Rate of shunt revision as a function of age in patients with shunted hydrocephalus due to myelomeningocele
}

\author{
Esther B. Dupepe, MD, MSPH, ${ }^{1}$ Betsy Hopson, MSHA, ${ }^{2}$ James M. Johnston, MD,, ${ }^{1,2}$ \\ Curtis J. Rozzelle, MD, ${ }^{1,2}$ W. Jerry Oakes, MD, ${ }^{1,2}$ Jeffrey P. Blount, MD, ${ }^{1,2}$ and \\ Brandon G. Rocque, MD, MS 1,2

\begin{abstract}
'Department of Neurosurgery, and ${ }^{2}$ Section of Pediatric Neurosurgery, Children's Hospital of Alabama and the University of Alabama at Birmingham, Alabama
\end{abstract}

OBJECTIVE It is generally accepted that cerebrospinal fluid shunts fail most frequently in the first years of life. The purpose of this study was to describe the risk of shunt failure for a given patient age in a well-defined cohort with shunted hydrocephalus due to myelomeningocele (MMC).

METHODS The authors analyzed data from their institutional spina bifida research database including all patients with MMC and shunted hydrocephalus. For the entire population, the number of shunt revisions in each year of life was determined. Then the number of patients at risk for shunt revision during each year of life was calculated, thus enabling them to calculate the rate of shunt revision per patient in each year of life. In this way, the timing of all shunt revision operations for the entire clinic population and the likelihood of having a shunt revision during each year of life were calculated.

RESULTS A total of 655 patients were enrolled in the spina bifida research database, 519 of whom had a diagnosis of MMC and whose mean age was $17.48 \pm 11.7$ years (median 16 years, range $0-63$ years). Four hundred seventeen patients had had a CSF shunt for the treatment of hydrocephalus and thus are included in this analysis. There were 94 shunt revisions in the 1 st year of life, which represents a rate of 0.23 revisions per patient in that year. The rate of shunt revision per patient-year initially decreased as age increased, except for an increase in revision frequency in the early teen years. Shunt revisions continued to occur as late as 43 years of age.

CONCLUSIONS These data substantiate the idea that shunt revision surgeries in patients with MMC are most common in the 1st year of life and decrease thereafter, except for an increase in the early teen years. A persistent risk of shunt failure was observed well into adult life. These findings underscore the importance of routine follow-up of all MMC patients with shunted hydrocephalus and will aid in counseling patients and families.

http://thejns.org/doi/abs/10.3171/2016.8.FOCUS16257

KEY WORDS hydrocephalus; myelomeningocele; shunt; aging; shunt revision

$\mathrm{M}$ YELOMENINGOCELE (MMC) is the most common form of neural tube defect. ${ }^{2,9}$ Despite a decreased prevalence in the United States in the era of post-folic acid fortification (http://www.cdc.gov/mmwr/ preview/mmwrhtml/mm6401a2.htm\#fig), ${ }^{2}$ MMC remains a common form of congenital anomaly in the United States ${ }^{14}$ and Europe. ${ }^{3}$ Hydrocephalus is present in $60 \%-$ 95\% of MMC patients and often necessitates shunt insertion for CSF diversion..$^{3,9,14}$ Complications of shunt place- ment such as shunt failures requiring revision contribute to morbidity and mortality in these patients. $3,6,6,9,14,22$

Multiple studies have shown that a very young patient age at initial shunt insertion is associated with an increased risk of revision. . $^{1,5,710,11,15-17,19}$ Additional studies support a young age at initial insertion as a risk factor for multiple revisions. ${ }^{21,23}$ Others have described a high risk of revision within 6 months from initial shunt insertion. ${ }^{1,12,17}$ Together, these findings suggest a temporal relationship, correlating

ABBREVIATIONS CPC = choroid plexus cauterization; $\mathrm{EMR}=$ electronic medical record; $\mathrm{ETV}=$ endoscopic third ventriculostomy; $\mathrm{MMC}=$ myelomeningocele; $\mathrm{NSBPR}=$ National Spina Bifida Patient Registry. 


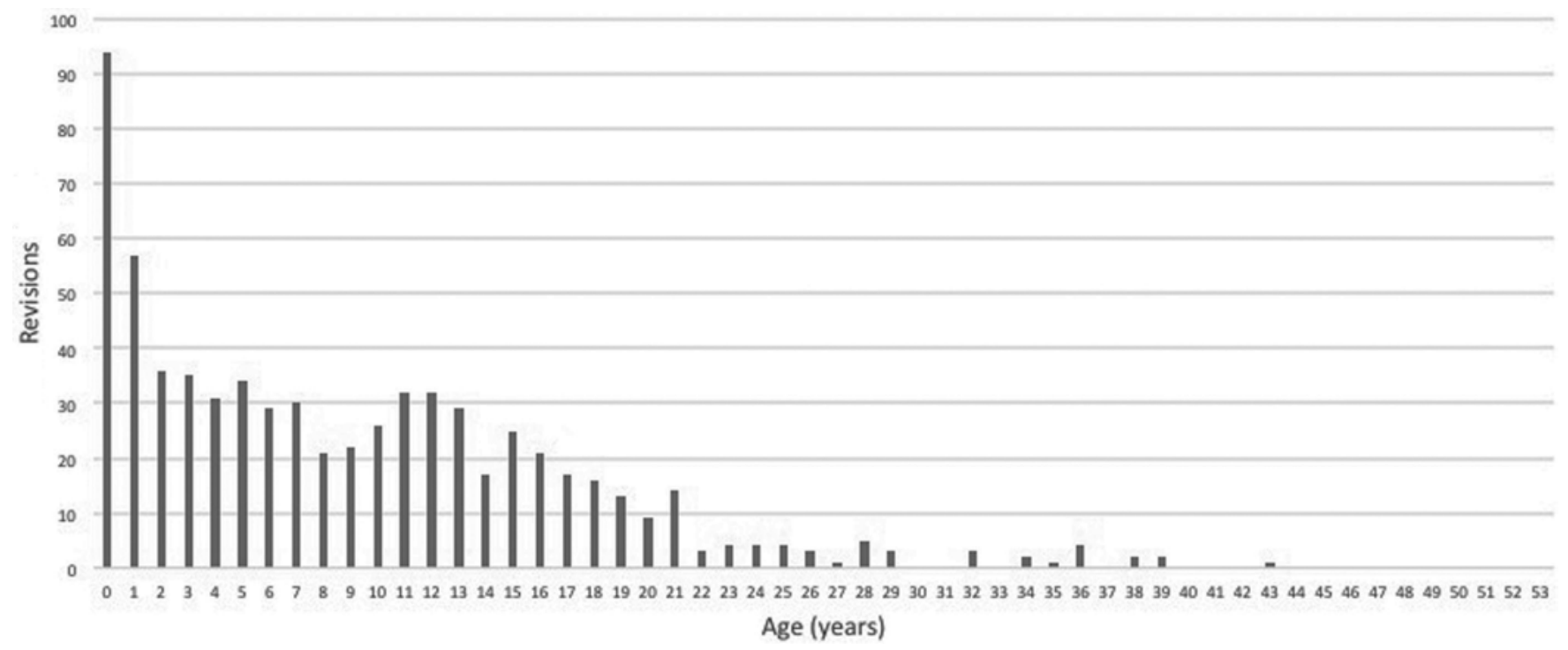

FIG. 1. Number of shunt revisions per year of life.

risk of revision and patient age. However, nearly all of the previous studies have ceased following patients at the time of the first shunt revision. Thus, while we have a great understanding of the effect of age and other factors on the risk of first shunt failure, we know relatively little about the continuing risks of shunt failure. Tuli et al. showed that a shorter time between shunt procedures was associated with a higher risk of subsequent failure, but their analysis did not go beyond 3 episodes of failure. Nor did it include patient age at the time of revision as a risk factor; rather, it only included age at the time of the first shunt placement. ${ }^{23}$

The present study aimed to evaluate the burden of shunt revision for a given patient age in a relatively homogeneous, single-institution sample of patients with MMC and hydrocephalus.

\section{Methods}

All patients with spina bifida, including both open MMC and other closed spinal dysraphisms (for example, spinal lipoma, split cord malformation, and so forth), are regularly followed in our institutional multidisciplinary spina bifida clinics. Patients under the age of 21 years are seen at least annually in the Children's of Alabama Spina Bifida Clinic, whereas those over 21 years old are seen annually in the University of Alabama Adult Spina Bifida Clinic. Patients evaluated in both locations are enrolled in the Centers for Disease Control and Prevention (CDC) National Spina Bifida Patient Registry (NSBPR). Discrete data are entered into the NSBPR electronic medical record (EMR). Certain data elements are de-identified and transmitted to the CDC, but all data remain available locally through the spina bifida research EMR. Our clinics enroll more than $99 \%$ of all patients into the NSBPR; therefore, the data in the registry reflect our entire clinic population.

Each patient visit to either the adult or pediatric spina bifida clinic includes a meeting with the clinic coordinator. Prior to each clinic visit, the patient's chart is reviewed for previous surgeries done since the last visit. During the clinic visit, this information is reviewed with the family to ensure that all surgical procedures the patient has undergone since the last clinic visit are recorded. In addition, at the time of the first clinic visit, all historical spina bifidarelated surgical procedures are recorded. When available, the exact surgery date is recorded and confirmed from the patient's medical record. When the patient and/or family cannot recall the exact timing of surgery, an estimate of the time is recorded and a data field is selected to indicate that the date is a family estimate rather than a confirmed date.

Using the NSBPR research EMR, we identified all patients with MMC and shunted hydrocephalus. Patients with closed spinal dysraphism (lipomyelomeningocele, split cord malformation, dermal sinus tract, and so forth) were excluded. Patients treated without a shunt, by endoscopic third ventriculostomy (ETV) with or without choroid plexus cauterization (CPC), were excluded as well. However, if a patient received a shunt after a failed ETV, the patient was included. We then identified each individual incidence of surgical hydrocephalus treatment for each patient. Those surgical treatment events for which no date or estimated date of surgery were available were excluded.

We determined the number of shunt revisions performed in our cohort in each year of life (Fig. 1). We then determined the number of patients who had reached that age or older, that is, those who had lived through that year of life (Fig. 2). Dividing the number of shunt revisions by the number of patients at risk for each year yields the average number of shunt revisions per patient in that year. In this way, all patients remain in the "at-risk" denominator regardless of previous shunt malfunction. This provides an estimate of the likelihood of having a shunt revision during each year of life for our entire population with MMC. A regression line was fit to the data using Microsoft Excel, with year of life on the $\mathrm{x}$-axis and number of shunt revisions on the y-axis.

Because the sample consists entirely of patients with MMC, we assumed that it was highly homogeneous, thus 


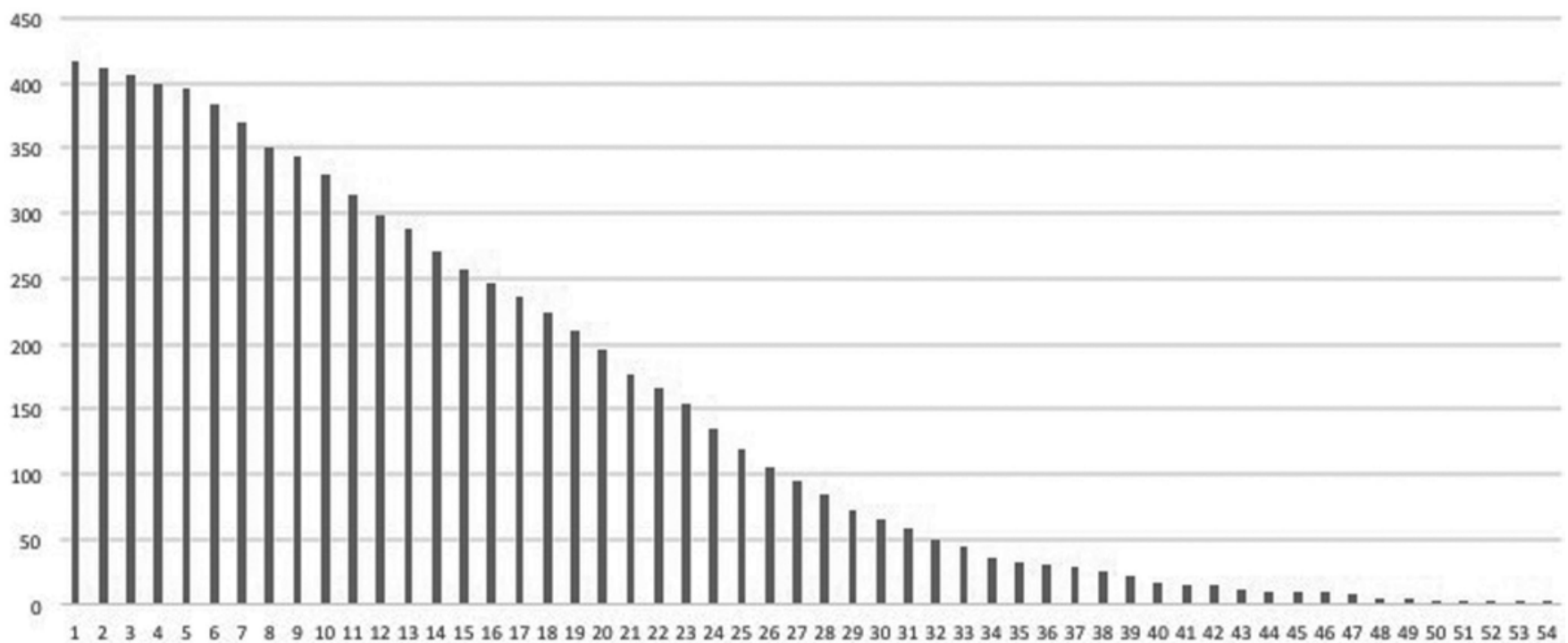

FIG. 2. Total number of patients (y-axis) at risk per year of life (x-axis).

limiting the value of assessing covariates. For example, previous studies have suggested that age at the time of shunt insertion and etiology of hydrocephalus are associated with shunt failure. Because all patients included this study have the same etiology (MMC), there is no value in assessing etiology as a covariate. Similarly, we assumed that the majority of patients had a shunt placed within the first few months of life, making evaluation of age at placement also of limited value.

\section{Results}

A total of 655 patients were enrolled in our spina bifida research database from October 2009 to May 2016. Patients with MMC make up the majority of patients included in the database (519 patients). The remaining patients have a closed spinal dysraphism diagnosis (lipomyelomeningocele, split cord malformation, dermal sinus tract, and so forth) and were not considered in this analysis. Baseline characteristics of all patients with MMC are presented in Table 1 . The mean age was 17.48 years (median 16.0 years, range $0-63$ years).

Four hundred seventeen $(80.3 \%)$ of the MMC patients had had at least 1 shunt operation and are included for analysis. An additional 38 patients were treated with ETV or ETV-CPC; the ETV failed in 18 (47.4\%) of these patients, who later required placement of a CSF shunt. There were 39 total instances of shunt revision for which no actual or estimated surgery date was available. These events were excluded from analysis.

There were 94 shunt revisions in the 1st year of life among 417 at-risk patients, which corresponds to a rate of 0.23 revisions per patient in that year of life. There were 57 shunt revisions in patients between 1 and 2 years old, with 411 patients at risk (0.14 revisions/patient/yr). The rate of shunt revisions per year continued to drop each year through 4 years of age. The rate of revisions per year increased in the early teen years, followed by a decrease through the late teen years and early 20s (Fig. 3). Fitting a logarithmic curve to these data yields a function to estimate the risk of shunt revision in any year of life $(y=-0.04$ $\ln ($ age $\left.)+0.17, \mathrm{R}^{2}=0.52\right)$. We observed higher numbers of shunt revisions per year from the late 20 s to early 40 s.

TABLE 1. Baseline characteristics in 519 patients with hydrocephalus due to MMC

\begin{tabular}{|c|c|}
\hline Parameter & Value \\
\hline \multicolumn{2}{|l|}{ Age in yrs } \\
\hline Mean (SD) & $17.48(11.7)$ \\
\hline Median (range) & $16.00(0-63)$ \\
\hline \multicolumn{2}{|l|}{$\operatorname{Sex}(\%)$} \\
\hline Male & $244(47)$ \\
\hline Female & $275(53)$ \\
\hline \multicolumn{2}{|l|}{ Race (\%) } \\
\hline White & $397(76.5)$ \\
\hline Black or African American & $92(17.7)$ \\
\hline Asian & $12(2.3)$ \\
\hline American Indian or Alaska native & $2(0.4)$ \\
\hline Multiracial & $12(2.3)$ \\
\hline Other/unknown & $4(0.8)$ \\
\hline \multicolumn{2}{|l|}{ Level of lesion (\%) } \\
\hline Sacral (foot plantar flexion present) & Lt 98 (18.9); rt 101 (19.5) \\
\hline Low lumbar (foot dorsiflexion present) & Lt 78 (15.0); rt 71 (13.7) \\
\hline Mid-lumbar (knee extension present) & Lt 138 (26.8); rt 149 (28.7) \\
\hline High lumbar (hip flexion present) & Lt 43 (8.3); rt 41 (7.9) \\
\hline Thoracic (flaccid lower extremities) & Lt 153 (29.5); rt 149 (28.7) \\
\hline Missing data & Lt 8 (1.5); rt 8 (1.5) \\
\hline \multicolumn{2}{|l|}{ Payer type (\%) } \\
\hline Medicaid & $323(62.2)$ \\
\hline Medicare & $41(7.9)$ \\
\hline Private insurance & $147(28.3)$ \\
\hline Missing data & $8(1.5)$ \\
\hline
\end{tabular}




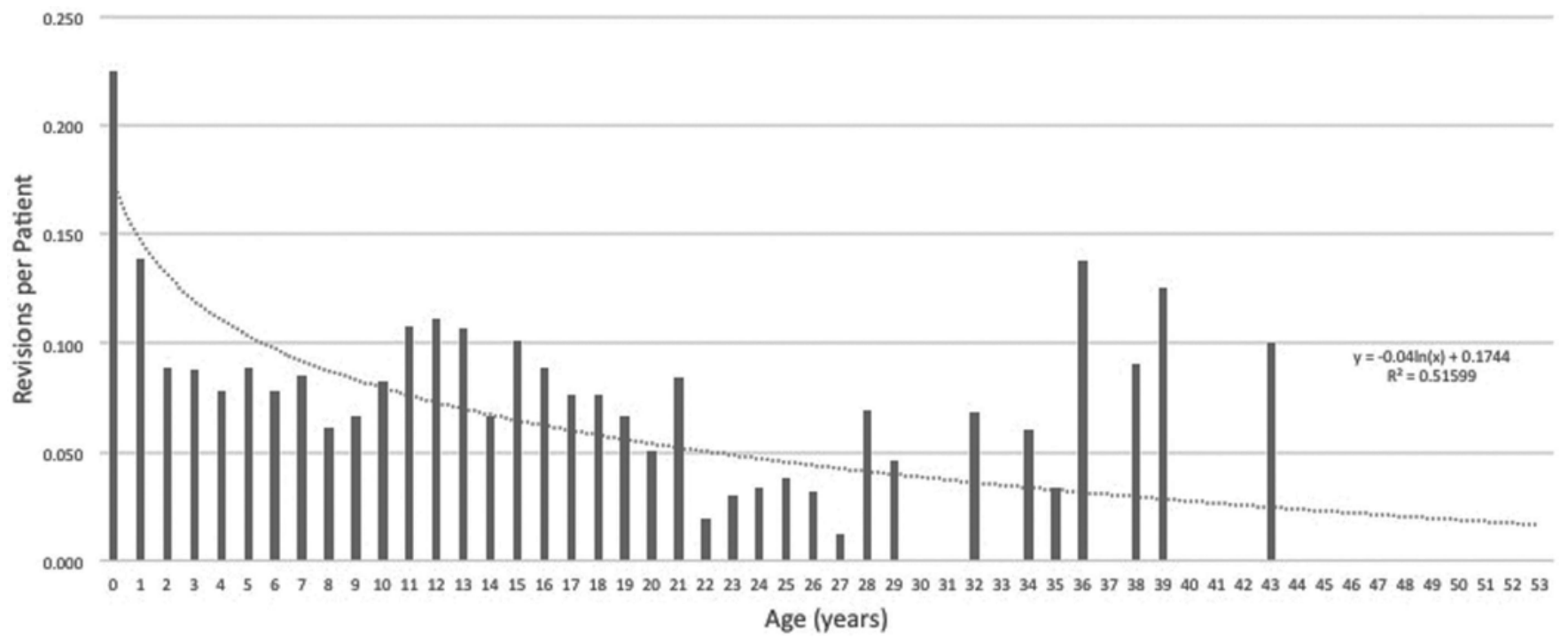

FIG. 3. Average shunt revisions per patient per year (number of shunt revisions per year of life/number of patients at risk).

However, there are substantially fewer patients at risk in these older age groups, so a few shunt revisions have the potential to increase the revision rate per patient substantially.

\section{Discussion}

The introduction of ventriculoperitoneal shunting as a treatment for hydrocephalus changed a fatal disease into a manageable chronic condition. Shunts, along with clean intermittent bladder catheterization, have facilitated longterm survival in patients with MMC. Nevertheless, complications of ventriculoperitoneal shunt placement continue to play a role in the morbidity and mortality of this condition. ${ }^{3,22}$ Furthermore, there is evidence to support an association between increasing numbers of shunt revisions and decreasing cognitive performance with lower scores on neuropsychological testing. ${ }^{6,8,14}$ Elucidating factors that contribute to complications including shunt malfunction may help minimize risk and will provide valuable information for counseling patients and their families.

While many studies have highlighted younger age as a risk factor for shunt failure and revision, to our knowledge no previous study has attempted to assess the rate of shunt revision as a function of age. ${ }^{1,17,18,21,23}$ In the present study, we have shown that among MMC patients with shunted hydrocephalus, the rate of shunt revision is highest in the first few years and declines thereafter. For pediatric neurosurgeons accustomed to treating this population, this result is likely intuitive and consistent with observations from their practice.

The majority of the existing literature examining shunt failure has performed survival analysis in which only the first revision after shunt placement was considered. These studies cannot capture the burden of subsequent revisions. Many neurosurgeons are familiar with the "difficult" shunt case, which returns for multiple revisions over the course of months. While these cases may not represent the typical experience of a patient with shunted hydrocepha- lus, it is important to factor them into the analysis of shunt revisions. Previous work by Tuli et al. showed that patients with an interval of less than 6 months between shunt operations have a higher risk for subsequent operation than those with more than a 6-month interval. ${ }^{23}$ However, there is no established way to predict which cases are likely to become "difficult." Thus, we believe that it is important to include patients with multiple revisions in our analysis. Our methodology allows for the inclusion of all shunt revisions, and thus gives a fuller picture of the burden of shunt failure. In other words, a single patient having multiple revisions in the same year leads to a higher average revision rate in that year. In the present study we include both high- and low-revision-rate patients, affording us a clearer picture of the average revision rate.

Interestingly, we observed an increase in the rate of shunt revisions in the early teen years $(0.11$ revisions per patient in years 11, 12, and 13; Figs. 1-2). Studies examining shunt revision that define the first event as the final end point cannot address this period of life in detail. It is typically a period of growth and hormonal changes, and it is possible that these factors affect the likelihood of shunt failure. The implications of this are potentially important. In general, symptoms of shunt failure are similar at any age, and our present work does not imply that one should treat patients with these symptoms differently based on age. However, patients with MMC may have shunt failure that presents with subtler symptoms. During early puberty, it may be easy to attribute these symptoms to factors other than hydrocephalus. Given that this age is a time of potentially increased risk of shunt failure, continued vigilance on the part of parents and providers is warranted.

This study represents one of the largest examinations of the experience of adult MMC patients with hydrocephalus, including 166 patients with an age 21 years or older. Hydrocephalus has been shown to have an association with a lower quality of life in children with MMC and with a lower likelihood of living independently, having a partner, and of reproducing in adults with MMC.,20 We 


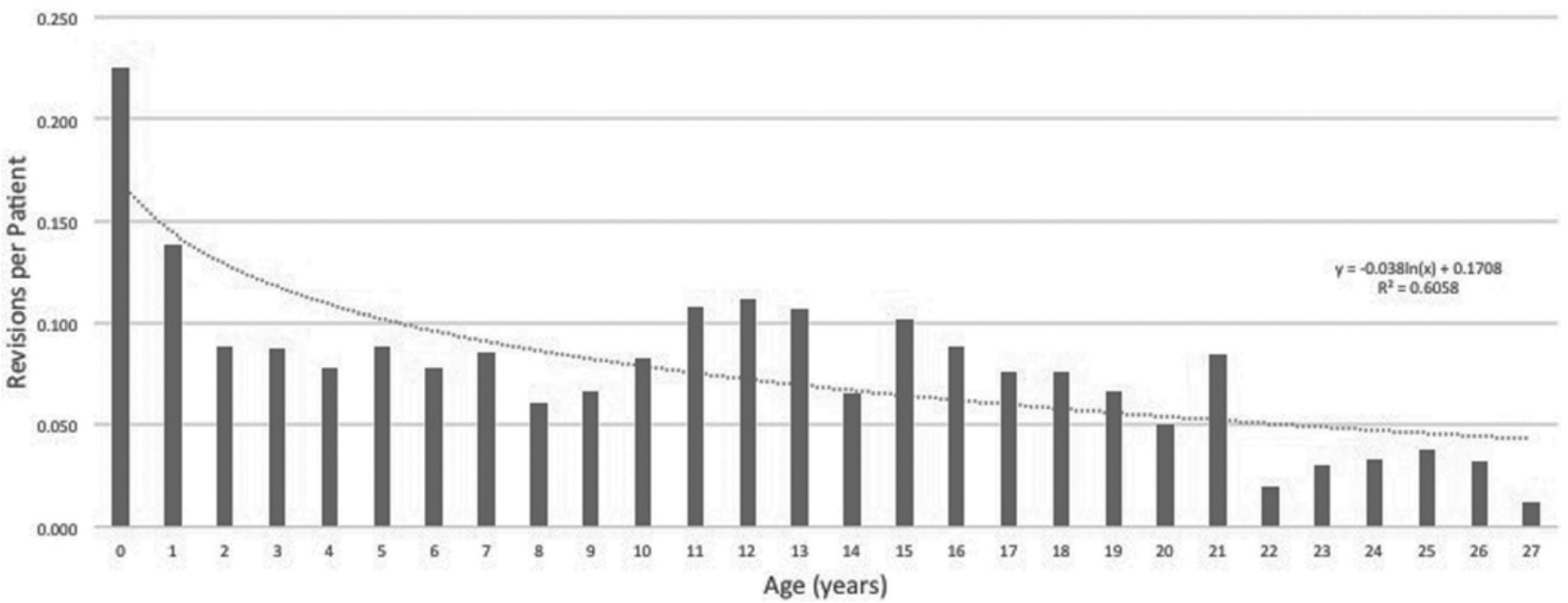

FIG. 4. Average shunt revisions per patient per year (number of shunt revisions per year of life/number of patients at risk) in patients with an age $\leq 27$ years.

have observed adults experiencing shunt failure as late as age 43 years. The high rates of shunt failure over the age of 30 years must be carefully considered (Fig. 3). Because of low numbers of patients at risk (Fig. 2), a small number of revisions can lead to a large revision rate per year. Indeed, excluding the oldest $20 \%$ of patients (over age 27 years) yields a shunt failure curve with a better fit and smooth tail $\left(R^{2}=0.61\right.$; Fig. 4). However, there were a total of 27 shunt revisions in patients 28 years and older. A study of the long-term follow-up of 128 adults with hydrocephalus treated in childhood (including 33\% of MMC patients) showed a nontumor mortality rate of 39\% over 40 years, with $8 \%$ mortality considered to be "shunt related." 13 Our data support the notion that there is no age over which shunt failure is no longer a risk. We believe it is crucial to continue routine follow-up of adult MMC patients with shunted hydrocephalus indefinitely. Moreover, neurosurgeons who may be less familiar with MMC patients must remain aware of the potential for shunt failure even in later years.

\section{Study Limitations}

This study uses retrospective data from a single institution. While episodes of shunt surgery are meticulously documented by the coordinator at the time of every multidisciplinary spina bifida clinic and confirmed with the medical record whenever possible, it is impossible to prevent recall bias.

Our evaluation is limited to patients with MMC and thus cannot address the role that the etiology of hydrocephalus may play in the rate of shunt revision. While some studies have suggested that patients with open neural tube defects such as MMC have a higher risk for revision, ${ }^{17,18,21}$ others have suggested that etiology is not an independent risk factor for shunt revision. ${ }^{16,19}$ Furthermore, because we included only patients with MMC, the generalizability of our findings is limited.

In our calculation of the number of patients at risk for shunt failure in each year of life, we assumed that all pa- tients had received a shunt within the 1st year of life. Because all of the patients had MMC, it was probably a valid assumption. However, if a patient did not receive a shunt until later in life, our assumption would lead to a higher estimated number of "at-risk" patients and thus a lower rate of revision per year. The effect of this should decrease in later years of life because fewer MMC patients are expected to receive new shunts later in life. Considering the curve depicted in Fig. 3, our assumption may have made the curve start at a lower point in year 0 and decline less sharply.

Previous reports support variation in rates of shunt revision surgery between high- and low-volume centers, ${ }^{1}$ which may influence our results. Additionally, our study is limited to MMC and our findings cannot be generalized to all patients with hydrocephalus managed with a shunt.

\section{Conclusions}

We have presented data from a population of adults and children with MMC, defining the rate of shunt revision in each year of life. Risk of shunt failure is highest in the 1st year of life and declines thereafter. We observed a period of increased risk in the early teen years, as well as continued potential for shunt failure into middle age. We believe it is critical for adult MMC patients with shunted hydrocephalus to receive routine follow-up care. These findings will facilitate patient education and counseling regarding potential complications associated with the surgical management of hydrocephalus in patients with MMC.

\section{Acknowledgments}

Dr. Rocque is supported by NIH Grant No. 1KL2TR001419 and by the Kaul Pediatric Research Institute of the Children's of Alabama.

\section{References}

1. Berry JG, Hall MA, Sharma V, Goumnerova L, Slonim AD, Shah SS: A multi-institutional, 5-year analysis of initial and 
multiple ventricular shunt revisions in children. Neurosurgery 62:445-454, 2008

2. Bowman RM, Boshnjaku V, McLone DG: The changing incidence of myelomeningocele and its impact on pediatric neurosurgery: a review from the Children's Memorial Hospital. Childs Nerv Syst 25:801-806, 2009

3. Chakraborty A, Crimmins D, Hayward R, Thompson D: Toward reducing shunt placement rates in patients with myelomeningocele. J Neurosurg Pediatr 1:361-365, 2008

4. Cope H, McMahon K, Heise E, Eubanks S, Garrett M, Gregory S, et al: Outcome and life satisfaction of adults with myelomeningocele. Disabil Health J 6:236-243, 2013

5. Cozzens JW, Chandler JP: Increased risk of distal ventriculoperitoneal shunt obstruction associated with slit valves or distal slits in the peritoneal catheter. J Neurosurg 87:682-686, 1997

6. Dennis M, Jewell D, Drake J, Misakyan T, Spiegler B, Hetherington $\mathrm{R}$, et al: Prospective, declarative, and nondeclarative memory in young adults with spina bifida. J Int Neuropsychol Soc 13:312-323, 2007

7. Di Rocco C, Marchese E, Velardi F: A survey of the first complication of newly implanted CSF shunt devices for the treatment of nontumoral hydrocephalus. Cooperative survey of the 1991-1992 Education Committee of the ISPN. Childs Nerv Syst 10:321-327, 1994

8. Hetherington R, Dennis M, Barnes M, Drake J, Gentili F: Functional outcome in young adults with spina bifida and hydrocephalus. Childs Nerv Syst 22:117-124, 2006

9. Liptak GS, Dosa NP: Myelomeningocele. Pediatr Rev 31:443-450, 2010

10. Liptak GS, Masiulis BS, McDonald JV: Ventricular shunt survival in children with neural tube defects. Acta Neurochir (Wien) 74:113-117, 1985

11. Liptak GS, McDonald JV: Ventriculoperitoneal shunts in children: factors affecting shunt survival. Pediatr Neurosci 12:289-293, 1985-1986

12. Park MK, Kim M, Park KS, Park SH, Hwang JH, Hwang SK: A retrospective analysis of ventriculoperitoneal shunt revision cases of a single institute. J Korean Neurosurg Soc 57:359-363, 2015

13. Paulsen AH, Lundar T, Lindegaard KF: Pediatric hydrocephalus: 40-year outcomes in 128 hydrocephalic patients treated with shunts during childhood. Assessment of surgical outcome, work participation, and health-related quality of life. J Neurosurg Pediatr 16:633-641, 2015

14. Phillips BC, Gelsomino M, Pownall AL, Ocal E, Spencer HJ, O'Brien MS, et al: Predictors of the need for cerebrospinal fluid diversion in patients with myelomeningocele. J Neurosurg Pediatr 14:167-172, 2014

15. Piatt JH Jr: Cerebrospinal fluid shunt failure: late is different from early. Pediatr Neurosurg 23:133-139, 1995

16. Piatt JH Jr, Carlson CV: A search for determinants of cerebrospinal fluid shunt survival: retrospective analysis of a 14-year institutional experience. Pediatr Neurosurg 19:233242, 1993

17. Reddy GK, Bollam P, Caldito G: Long-term outcomes of ventriculoperitoneal shunt surgery in patients with hydrocephalus. World Neurosurg 81:404-410, 2014

18. Reddy GK, Bollam P, Caldito G, Guthikonda B, Nanda A: Ventriculoperitoneal shunt surgery outcome in adult transition patients with pediatric-onset hydrocephalus. Neurosurgery 70:380-389, 2012

19. Riva-Cambrin J, Kestle JRW, Holubkov R, Butler J, Kulkarni $\mathrm{AV}$, Drake J, et al: Risk factors for shunt malfunction in pediatric hydrocephalus: a multicenter prospective cohort study. $\mathbf{J}$ Neurosurg Pediatr 17:382-390, 2016

20. Rocque BG, Bishop ER, Scogin MA, Hopson BD, Arynchyna AA, Boddiford CJ, et al: Assessing health-related quality of life in children with spina bifida. J Neurosurg Pediatr 15:144-149, 2015

21. Shah SS, Hall M, Slonim AD, Hornig GW, Berry JG, Sharma $\mathrm{V}$ : A multicenter study of factors influencing cerebrospinal fluid shunt survival in infants and children. Neurosurgery 62:1095-1103, 2008

22. Tuli S, Drake J, Lamberti-Pasculli M: Long-term outcome of hydrocephalus management in myelomeningoceles. Childs Nerv Syst 19:286-291, 2003

23. Tuli S, Drake J, Lawless J, Wigg M, Lamberti-Pasculli M: Risk factors for repeated cerebrospinal shunt failures in pediatric patients with hydrocephalus. J Neurosurg 92:31-38, 2000

\section{Disclosures}

The authors report no conflict of interest concerning the materials or methods used in this study or the findings specified in this paper.

\section{Author Contributions}

Conception and design: Rocque, Hopson. Acquisition of data: Rocque, Hopson. Analysis and interpretation of data: Rocque, Dupepe. Drafting the article: Dupepe. Critically revising the article: Rocque, Dupepe, Johnston, Rozzelle, Oakes. Reviewed submitted version of manuscript: all authors. Approved the final version of the manuscript on behalf of all authors: Rocque. Statistical analysis: Rocque. Administrative/technical/material support: Hopson, Johnston, Rozzelle, Oakes, Blount. Study supervision: Rocque.

\section{Correspondence}

Brandon G. Rocque, Department of Neurosurgery, University of Alabama at Birmingham, 1600 7th Ave. South, Lowder 400, Birmingham, AL 35233-5294. email: brandon.rocque@childrensal. org. 